\title{
Wheel Abrasion Experiment Metals Selection for Mars Pathfinder Mission
}

\author{
Aloysius F. Hepp \\ Lewis Research Center \\ Cleveland, Ohio \\ Navid S. Fatemi \\ Essential Research, Inc. \\ Cleveland, Ohio
}

David M. Wilt and Dale C. Ferguson

Lewis Research Center

Cleveland, Ohio

Richard W. Hoffman

Essential Research, Inc.

Cleveland, Ohio

Maria M. Hill

Kent State University

Kent, Ohio

Alain E. Kaloyeros

State University of New York at Albany

Albany, New York

Prepared for the 1996 Fall Meeting sponsored by the Materials Research Society Boston, Massachusetts, December 2-6, 1996

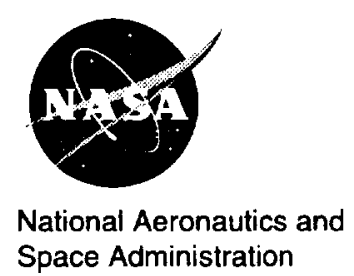


.

. 


\section{WHEEL ABRASION EXPERIMENT METALS SELECTION FOR MARS PATHFINDER MISSION}

ALOYSIUS F. HEPP*, NAVID S. FATEMI**, DAVID M. WILT*, DALE C. FERGUSON*, RICHARD W. HOFFMAN**, MARIA M. HILL ${ }^{\ddagger}$ AND ALAIN E. KALOYEROS ${ }^{\ddagger}$

*NASA Lewis Research Center, M.S. 302-1, Cleveland, OH 44135; **Essential Research, Inc., 23811 Chagrin Blvd., Suite 220, Cleveland, $\mathrm{OH} 44122$; ${ }^{\ddagger}$ Kent State University; School of Technology; Kent, OH 44242; ${ }^{\ddagger}$ University at Albany - SUNY, Department of Physics, 1400 Washington Avenue, Albany, NY 12222

\section{ABSTRACT}

A series of metals was examined for suitability for the Wheel Abrasion Experiment, one of ten microrover experiments of the Mars Pathfinder Mission. The seven candidate metals were: Ag, Al, $\mathrm{Au}, \mathrm{Cu}, \mathrm{Ni}, \mathrm{Pt}$, and $\mathrm{W}$. Thin films of candidate metals from 0.1 to 1.0 micrometer thick were deposited on black anodized aluminum coupons by e-beam and resistive evaporation and chemical vapor deposition. Optical, corrosion, abrasion, and adhesion criteria were used to select $\mathrm{Al}, \mathrm{Ni}$, and Pt. A description is given of the deposition and testing of thin films, followed by a presentation of experimental data and a brief discussion of follow-on testing and flight qualification.

\section{INTRODUCTION}

After a twenty-year hiatus [1], the United States will return to the surface of Mars with the December 1996 launch of the Mars Pathfinder Mission, the second launch in the NASA Discovery Program. The mission will focus on the demonstration of key technologies and concepts for eventual use in future missions to Mars that employ scientific landers. Pathfinder will land several instruments as well as a microrover (named Sojourner) to investigate the Martian atmosphere, surface meteorology, surface geology, form, and structure, and the elemental composition of the Martian rocks and soil, see figure 1 [2].

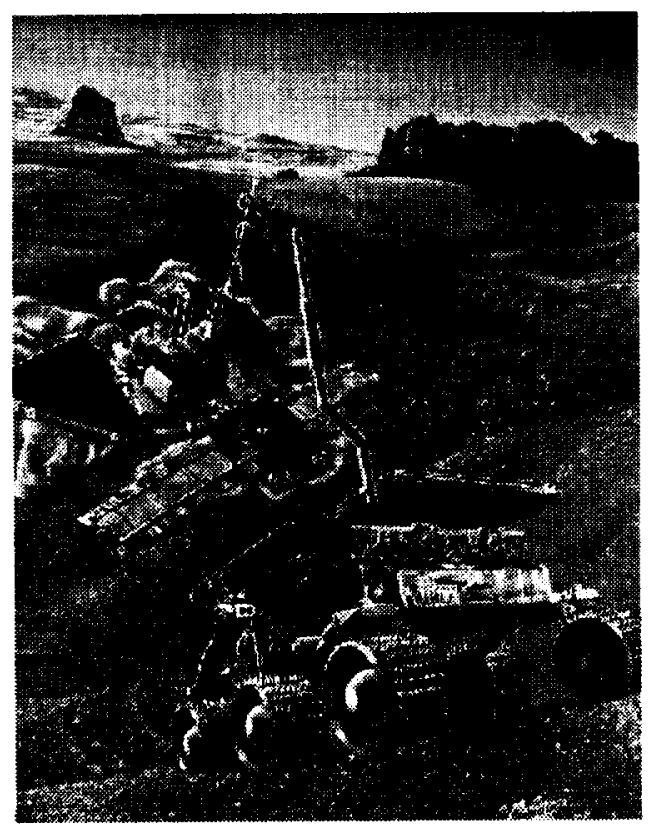

Figure 1.-Artist's conception of Sojourner microrover exploring surface of Mars. 
While it is doubtful that any new light will be shed on the possibility that carbon-based life may have or currently does exist on Mars, the recent announcement and publication of evidence indicative of ancient primitive life on Mars [3] increased interest in the Mars Pathfinder Mission by a factor of five [4]. After the July 1997 landing, the microrover will be deployed to explore the Martian surface. The Sojourner is equipped with ten experiments, three of which were designed and built at NASA Lewis Research Center. The purpose of one of these, the Wheel Abrasion Experiment (WAE) is to determine the mechanical properties of Martian dust and its ability to wear metal surfaces such as those found in propulsion, structural, and power systems. The wear is to be detected by a photocell through reduction of reflectance of thin metal films on a black substrate (attached to a microrover wheel) as the wheel rolls over the surface of Mars.

A series of metals was examined for suitability for the WAE. The seven candidate metals were: $\mathrm{Ag}, \mathrm{Al}, \mathrm{Au}, \mathrm{Cu}, \mathrm{Ni}, \mathrm{Pt}$, and $\mathrm{W}$. Thin films of candidate metals from 0.1 to 1.0 micrometer thick were deposited on black anodized aluminum coupons by e-beam and resistive evaporation and chemical vapor deposition. Optical, corrosion, abrasion, and adhesion criteria were used to select $\mathrm{Al}, \mathrm{Ni}$, and Pt. A description is given of the deposition and testing of thin films, followed by a presentation of experimental data and a brief discussion of follow-on testing and flight qualification.

\section{EXPERIMENTAL}

The coupons used for reflectance measurements were $0.3 \times 1.0 \times 6.0 \mathrm{~cm} 6061$-T6 aluminum that were black anodized according to specification MIL-A-8625-F, resulting in an alumina surface impregnated with black dye. Ag, Al, $\mathrm{Au}, \mathrm{Ni}$, and $\mathrm{Pt}$ were deposited by e-beam or resistive evaporation [5]. Chemical vapor deposition of $\mathrm{Cu}$ and $\mathrm{W}$ were accomplished on custom made systems as described previously [6]. Reflectance measurements were made on a Perkin Elmer Lambda 19 spectrophotometer (equipped with an integrating sphere to capture all reflected light). Metal films varied in thickness from 0.1 to 1.0 micrometer.

\section{RESULTS AND DISCUSSION}

Figure 2 is a plot of reflectance of the seven metals considered for the WAE as well as a spectrum of the bare black anodized aluminum surface. The metals were chosen to reflect a cross section of properties (melting point, hardness) and applications (structural, electronic, and propulsion). Because the photoresponse of the detector was not known at the time, a fairly broad spectral region was measured from the visible to the infrared, $400-1000 \mathrm{~nm}$.

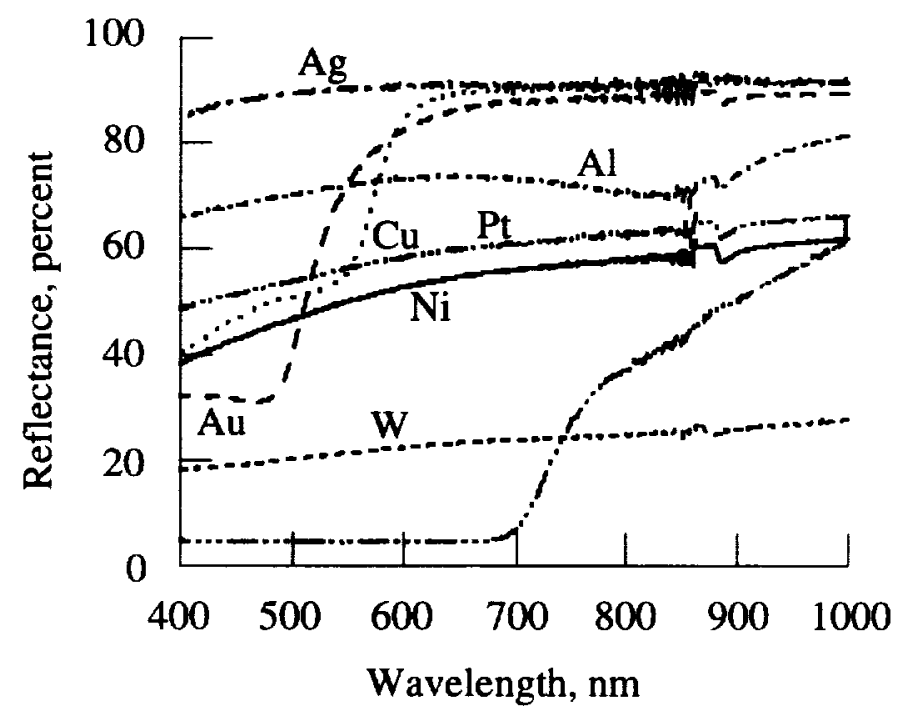

Figure 2.- Reflectance spectra of candidate metals and anodized $\mathrm{Al}$ from 400 to $100 \mathrm{~nm}$. 
After reflectance measurements were made, a crude adhesion test was conducted. This was done to assure reasonable sticking of the metal to the substrate and to preclude uneven wearing or spalling of the film upon abrasion. A strip of commercial adhesive tape was attached to coupons of each of the candidate metals and removed. Some care was taken to use approximately equal force to stick and remove the tape but the test was fairly simple. The results of the test were graded by visual inspection. Any peeling of greater than 50\% was considered unacceptable; peeling of 25 to 50 percent was considered poor but acceptable; peeling of 10 to 25 percent was considered good; and peeling under 10 percent was considered excellent. A further observation that was made was the corrosion or tarnishing of $\mathrm{Ag}$ [7] upon handling in the laboratory environment. Aside from cleaning the coupons before deposition of metal films no particular care was taken to control the environment of the samples. The reason for this is that flight hardware was to be handled under numerous environments from time of assembly to launch. In that time microrover and experiments on it were not going to be kept in stringently controlled environments. Therefore no particular controls were placed on the handling of the samples in order to detect any corrosion or other detrimental processes.

The results of optical measurements, adhesion test, other concerns as well as deposition method are listed in Table I. A result that caused the exclusion of a metal from consideration for the WAE is highlighted. The film thicknesses ranged from 0.1 to 1.0 micrometers. This range was chosen to provide for some wear for harder metals while preventing excessive wear for softer metals. As the timeframe approached for building of actual flight hardware, a GaAs photodetector was chosen for the WAE. Because of the optical response of the detector (GaAs band edge at $860 \mathrm{~nm}$ ) [8], an average reflectance was determined for each metal in the range of $400-800 \mathrm{~nm}$.

Table I. Summary of Test Data of Seven Candidate Metals for Mars Pathfinder WAE

\begin{tabular}{|c|c|c|c|c|c|}
\hline Metal & Deposition Method & $\underline{\text { Avg. R }(400-800 \mathrm{~nm})}$ & Adhesion & Other & WAE \\
\hline $\mathrm{Ag}$ & Evaporation & 0.90 & Poor & Tarnished & No \\
\hline $\mathrm{Al}$ & Evaporation & 0.71 & Excellent & ----- & Yes \\
\hline $\mathrm{Au}$ & Evaporation & 0.67 & Unacceptable & ----- & No \\
\hline $\mathrm{Cu}$ & CVD & 0.70 & Good & ----- & No \\
\hline $\mathrm{Ni}$ & Evaporation & 0.51 & Good & ----- & Yes \\
\hline $\mathrm{Pt}$ & Evaporation & 0.45 & Excellent & ----- & Yes \\
\hline W & CVD & 0.22 & Good & ----- & No \\
\hline
\end{tabular}

The three metals, $\mathrm{Al}, \mathrm{Ni}$, and $\mathrm{Pt}$ that were selected from the seven considered represent a good cross-section of metals that vary in properties and that span the range of electronic, structural, and propulsion applications. Aluminum was chosen because it adhered well to the substrate, had a relatively high reflectance, and a flat reflectance response. Silver while it was the most reflective metal examined was eliminated because of its tarnishing and relatively poor adhesion. Gold was eliminated because of a lack of adhesion to the anodized aluminum and light absorption below $600 \mathrm{~nm}$. Copper, the other colored metal, was also eliminated because of light absorption among other reasons. While $\mathrm{Ni}$ and $\mathrm{Pt}$ were not as reflective as $\mathrm{Cu}$, they were chosen because they had relatively flat reflectance values throughout the visible and near-infrared spectrum. Also, because of the relatively low hardness of $\mathrm{Al}$ (2-2.9, Mohs [7]), it was decided to include metals with higher hardness values $(\mathrm{Cu}: 2.5-3, \mathrm{Pt}: 4.3 ; \mathrm{Ni}: 5.5-6$ [7]). Tungsten was eliminated because of low reflectance $(0.22)$. 
A parallel effort to the selection of metals for the WAE involved preliminary testing of the optical output from coupons (reflectance) of leading metal candidates during a simulated abrasion process. Four metal coupons (Ag, $\mathrm{Al}, \mathrm{Cu}$, and $\mathrm{Pt}$ ) were abraded with commercial 500 grit $\mathrm{SiC}$ sandpaper. The coupons were laid on a flat surface and lightly scratched with sandpaper. As with the adhesion test, this was a crude approximation of a thin metal film being abraded as it rolls on the surface of Mars. Figure 3 shows results for $\mathrm{Al}$ and $\mathrm{Pt}$ as the films were scratched 5, 10, 25, and 40 times, this was meant to simulate the same number of revolutions. Several abrasion test were repeated and the results were fairly consistent: 5 passes of 500 grit $\mathrm{SiC}$ reduced the reflectance by $15-25 \% ; 40$ passes of 500 grit $\mathrm{SiC}$ reduced the reflectance $>90 \%$. The wear appeared to be fairly uniform throughout the sample. The objective of the test was achieved in that it was demonstrated that smooth wear of the samples would result in a gradual reduction in the reflectance of the metal films.
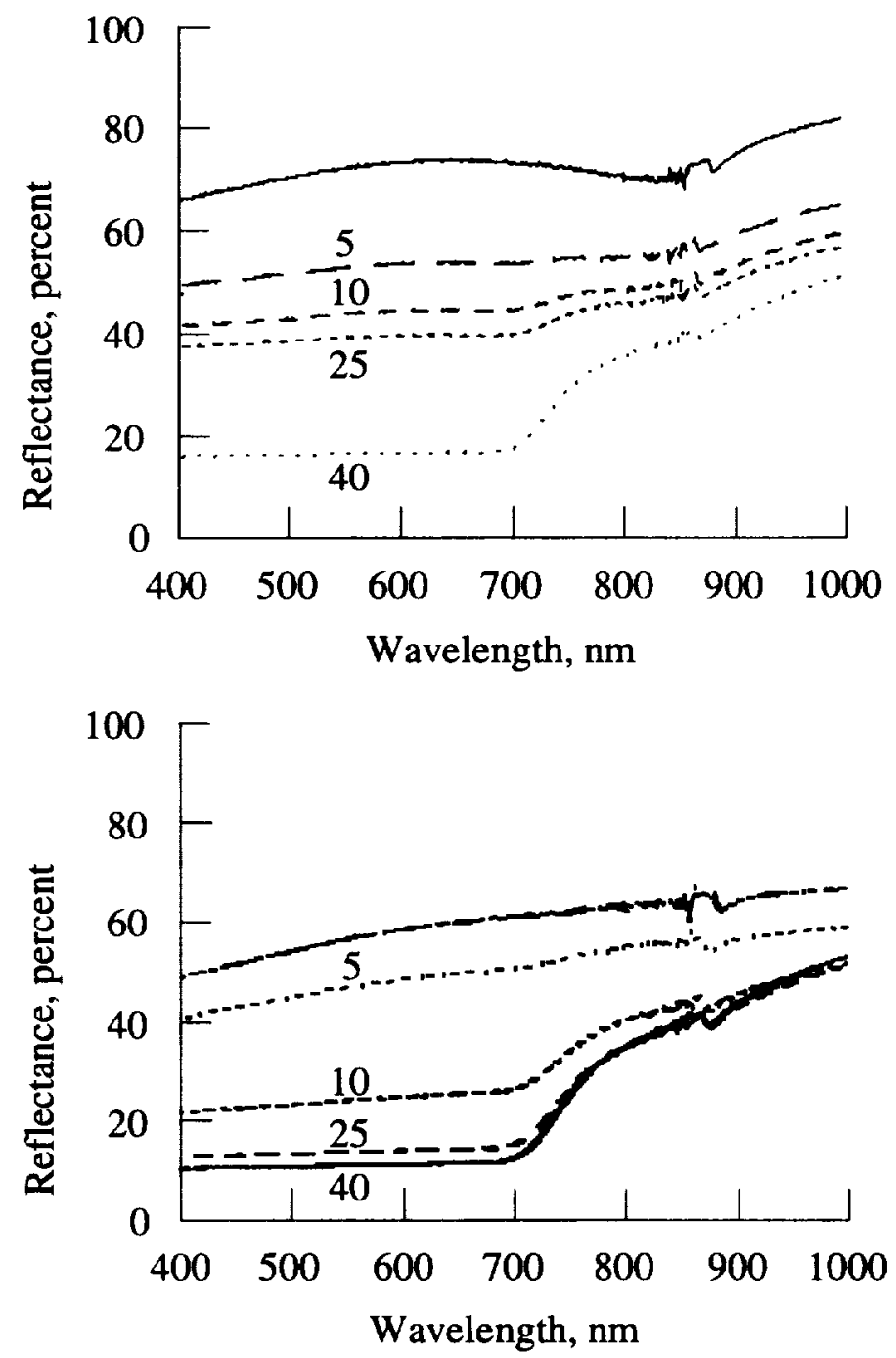

Figure 3.-Reflectance spectra of $\mathrm{Al}$ and $\mathrm{Pt}$ with 5, 10, 25, and 40 passes over 500 grit SiC. 
At this phase of the project, simulated wheels were built and tested. An improved abrasion test involved dragging coupons of the selected metals under a load designed to approximate the weight of the microrover on Mars through a chamber with simulated Mars dust. The results of these tests were a smaller than expected abrasion of metal than expected based on the crude SiC abrasion tests. As the point of the mission was to get a range of wear from total to minimal, the microrover WAE wheel was designed to measure the wear of the three metals, $\mathrm{Al}, \mathrm{Ni}$, and $\mathrm{Pt}$ with a range of thickness from 200 to $1000 \AA$. This represents an order of magnitude reduction in the thickness of samples tested on coupons. However, this is reasonable when comparing the method of abrasion: scratching with sandpaper versus abrasion from dragging under a lighter load.(11.5 kg of mobile mass, approximately 10 pounds of load on Mars). Figure 4 shows a WAE system calibration using a wheel prototype and a photodetector.

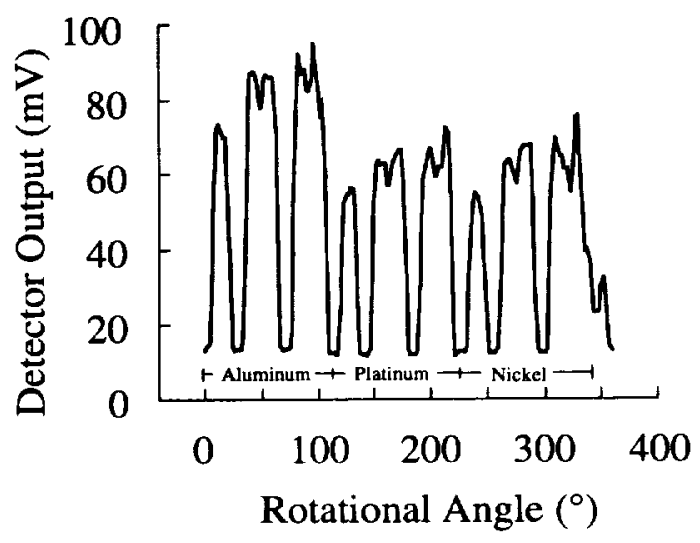

Figure 4.-WAE system calibration using prototype wheel and photodetector.

The final flight hardware was built using three strips of 7071-T6 aluminum that were black anodized using the same material as the sample coupons. The strips were $25 \mathrm{~mm} \times 120 \mathrm{~mm} \times$ $0.25 \mathrm{~mm}$. There are five thicknesses of each metal: $200 \AA, 300 \AA, 450 \AA, 700 \AA$, and $1000 \AA$. The pattern of each strip is: BMBMMBMM where the thickness increases and $B$ indicates a spot that was left bare, this was done to aid in the identification of the metals on the wheel. A WAE flight wheel is shown in figure 5. A recent picture of the microrover during assembly at the Jet Propulsion Laboratory (JPL) with the WAE visible is shown in figure 6.

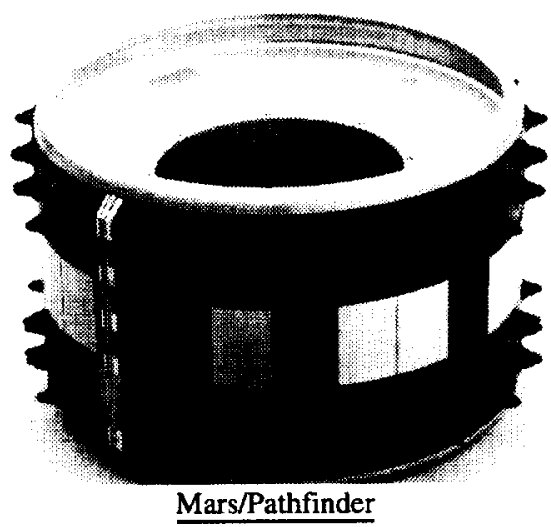

Wheel Abrasion Experiment (WAE) NASA Lewis Reasearch Center Wheel

1 inch

Figure 5.-WAE flight wheel showing pattern of black and metal-coated areas. 


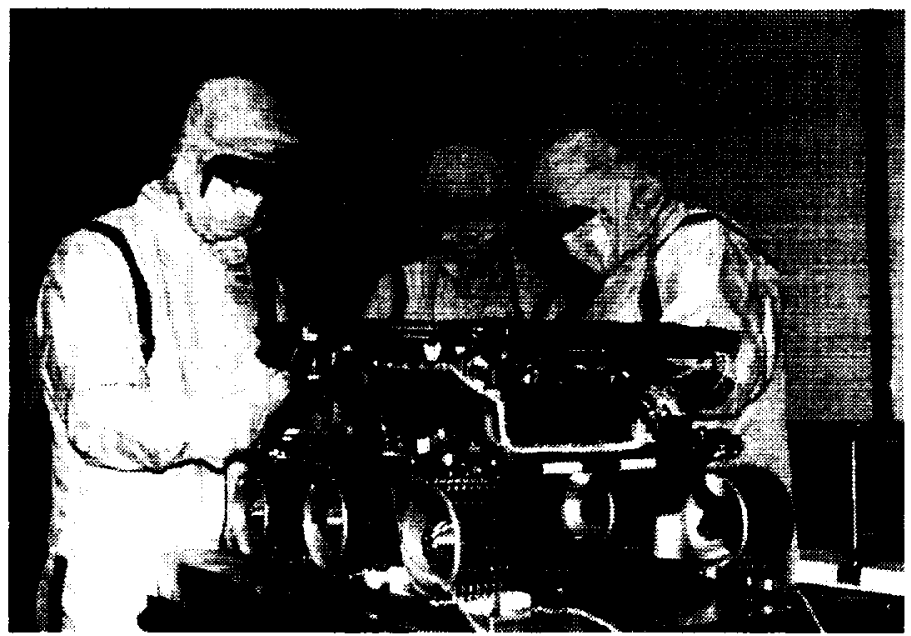

Figure 6.-Sojourner microrover during assembly at JPL with WAE visible (middle wheel).

\section{CONCLUSIONS}

Using simple optical and mechanical tests, $\mathrm{Al}, \mathrm{Pt}$, and Ni were chosen for the WAE of the Mars Pathfinder Mission scheduled for a July 1997 landing. More sophisticated tests were used to design the final flight hardware. Tests of the WAE on a simulated microrover at JPL have been successful; the WAE is located on the right middle wheel of the Sojourner microrover. The WAE should provide insights into the interaction of Mars dust with metals to optimize the performance of future Mars lander missions. A full account of the WAE is forthcoming [8].

\section{ACKNOWLEDGEMENTS}

We acknowledge the management and staff of the Jet Propulsion Laboratory, the lead laboratory for the Mars Pathfinder Program, for their financial and technical support.

\section{REFERENCES}

1. For a recent overview of data from the 1976 Mars landers, Viking 1 and Viking 2, see: Mars, edited by H.H. Kieffer, B.M. Jakosky, C.W. Snyder, and M.S. Matthews, (University. of Arizona Press, Tucson, 1992) 1536 pp.

2. The Rover Team, J. Geophys. Res., in press.

3. D.S. McKay, E.K. Gibson, Jr., K.L. Thomas-Keprta, H. Vali, C.S. Romanek, S.J. Clemett, X.D.F. Chillier, C.R. Maechling, and R.N. Zare, Science 273, 924 (1996).

4. R. Anderson, JPL (private communication) based on number of visits to the Mars Pathfinder website (http://mpfwww.jpl.nasa.gov).

5. N.S. Fatemi and V.G. Weizer, J. Appl. Phys. 77, 5241 (1995).

6. B. Zheng, E.T. Eisenbraun, J. Liu and A.E. Kaloyeros, Appl. Phys. Lett. 61, 2175 (1992).

7. Handbook of Chemistry and Physics, 55th ed., edited by R.C. Weast, (Chemical Rubber Company Press, Cleveland, $\mathrm{OH}, 1974)$.

8. D.C. Ferguson, D.M. Wilt, A.F. Hepp, N.S. Fatemi, and J.C. Kolecki, J. Spacecraft and Rockets, in press. 


\section{Mars Pathfinder Fact Sheet}

\section{Mission Summary}

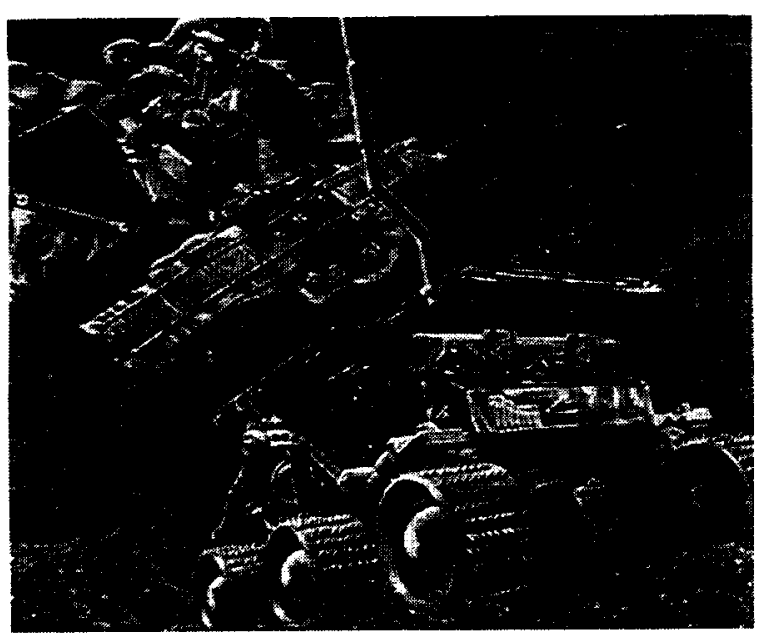

Artist's Concept of Lander and Microrover on Mars

$\mathrm{T}$ he Mars Pathfinder mission is the second launch in the Discovery Program, a NASA initiative for small planetary missions with a maximum three-year development cycle and a cost cap of $\$ 150$ million (FY92 equivalent \$) for development. The Mars Pathfinder project is managed for NASA by the Jet Propulsion Laboratory, California Institute of Technology, Pasadena, California.

The mission is primarily an engineering demonstration of key technologies and concepts for eventual use in future missions to Mars employing scientific landers. Pathfinder also delivers science instruments to the surface of Mars to investigate the structure of the Martian atmosphere, surface meteorology, surface geology, form, and structure, and the elemental composition of Martian rocks and soil. In addition, a free-ranging surface rover is deployed to conduct technology experiments and to serve as an instrument deployment mechanism.
The Project began the Assembly, Test, Launch, and Operations (ATLO) phase as scheduled on June 1, 1995. The activities include the assembly of the spacecraft, and system test and verification that includes both hardware and software. The tests are a rehearsal of the launch, cruise, TCM, and sol 1 and sol 2 phases of the mission.

\section{Mission Description}

The flight system is launched on a Delta II-7925

1 launch vehicle which includes a Payload Assist Module (PAM)-D upper stage, from the Cape Canaveral Air Force Station. The mission launch window is a 24-day period beginning on December 2, 1996.

After launch, the spacecraft requires 6 to 7 months to reach Mars, depending upon the exact launch date. During this phase, a series of four Trajectory Correction Maneuvers (TCM) is planned to fine-tune the flight path. Tracking, telemetry, and command operations with the spacecraft are conducted using the giant dish antennas of the NASA/JPL Deep Space Network (DSN). Upon arrival at Mars on July 4, 1997, the spacecraft will enter the Martian atmosphere, and then deploy the parachute, rocket braking system, and air bag system for landing. After landing, the airbags are retracted and the lander uprighted in preparation for the surface operations. At this point, the primary datataking phase begins, and continues for 30 Martian days or sols ( $1 \mathrm{sol}=24.6$ hours $)$.

During this time, the microrover is deployed and operated for at least 7 sols. If the lander and rover continue to perform well at the end of this period, the lander may continue to operate for up to one Martian year, and the microrover for up to 30 sols.

\section{Major Mission Characteristics}

Launch Period:

December 2-25, 1996

Launch Vehicle:

Trajectory:

Delta II - 7925

Primary Mission:

Complete Surface Mission:

End of Project:
6-7 months

Land on Mars -

July 4, 1997

August 1997

September 1998

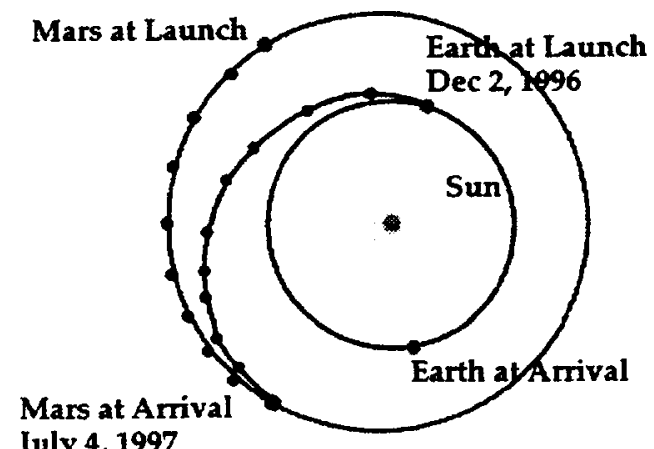

July 4, 1997

Interplanetary Trajectory 


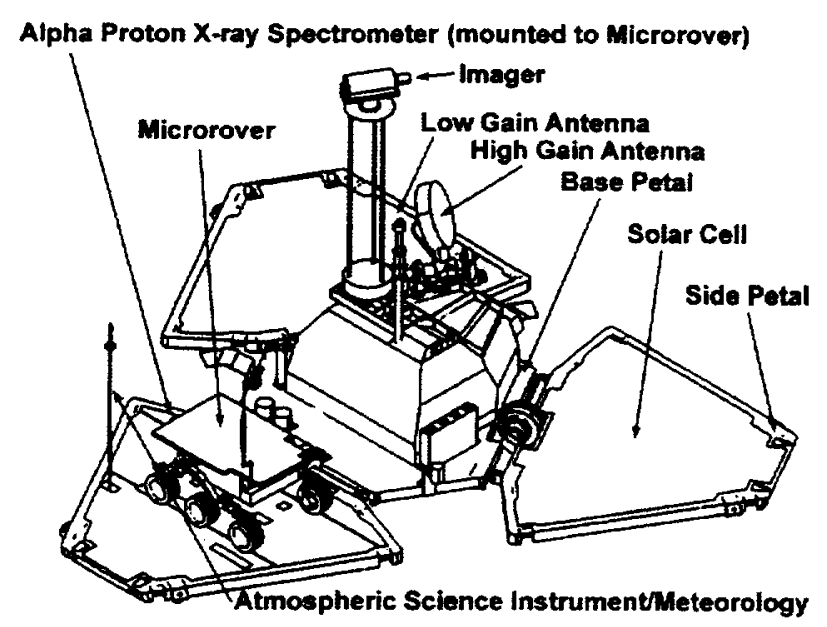

Mars Pathfinder Lander and Microrover

\section{Flight System Characteristics}

Launch Mass: $870 \mathrm{~kg}$ (includes propellant)

Entry Mass: $566 \mathrm{~kg}$

Lander Mass: $325 \mathrm{~kg}$

Basic Design:

- Aeroshell, parachute, solid rocket, and air bag entry, descent, and landing (EDL) system

- Self righting, tetrahedral lander

- Active thermal design for lander

- Free-ranging rover

Command and Data Handling: Integrated Attitude and Information Management System (AIM)

Computation: R6000 computer with VME bus, a range of 2.5 to 20 millions of instructions per second (mips), 128 Mbyte mass memory

Power: Gallium Arsenide/Germanium solar-powered cruise stage and lander

- Cruise power - 250 to 460 watts

- Surface daily energy available $-1080 \mathrm{~W}$-hours

Telemetry and Command:

Surface Operations Telemetry Rate via High

Gain Antenna (HGA), X-band: 1.2 to $12 \mathrm{~kb} / \mathrm{s}$ to

70-m Deep Space Network antenna

Surface Operations Command Rate via HGA,

$X$-band: $250 \mathrm{~b} / \mathrm{s}$

Propulsion:

- Monopropellant hydrazine used for cruise

- Eight 4.4-N thrusters

- Total $\Delta \mathrm{V}$ of $130 \mathrm{~m} / \mathrm{s}$

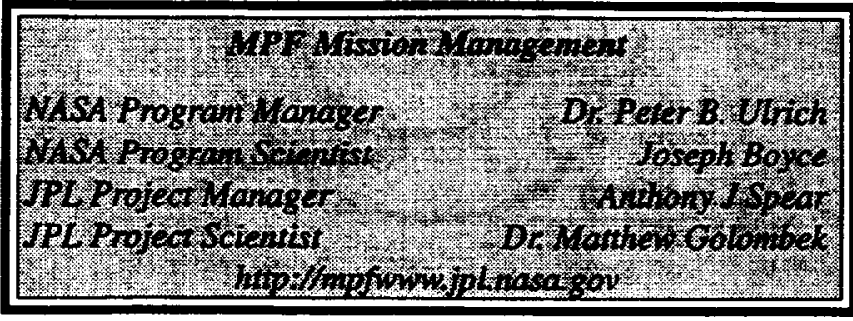

\section{Microrover Characteristics}

Total mass: $16 \mathrm{~kg}$

Mobile mass: $11.5 \mathrm{~kg}$ including APXS deployment mechanism and APXS instrument

Lander-Mounted Rover Equipment Mass: $4.5 \mathrm{~kg}$ including ultra-high frequency (UHF) modem and support structure

Autonomous Navigation: Onboard, using laser striping for obstacle detection

Mobility System: Six-wheel, rocker-bogie suspension

Command and Telemetry: UHF link with lander

Payload: Aft and fore cameras, APXS, APXS deploy ment mechanism

Power: $0.25-\mathrm{m}^{2}$ solar panels - peak power $16 \mathrm{~W}$-hours; primary battery - $150 \mathrm{~W}$-hours

Thermal Control: Three radioisotope heater units (RHU)

Computer Characteristics: $80 \mathrm{C} 85,0.1 \mathrm{mips}, 0.5$ Mbyte RAM mass storage, $0.5 \mathrm{~kg}, 1.5 \mathrm{~W}$

Surface Operations Time: 10 a.m. to 2 p.m. each Martian day (sol)

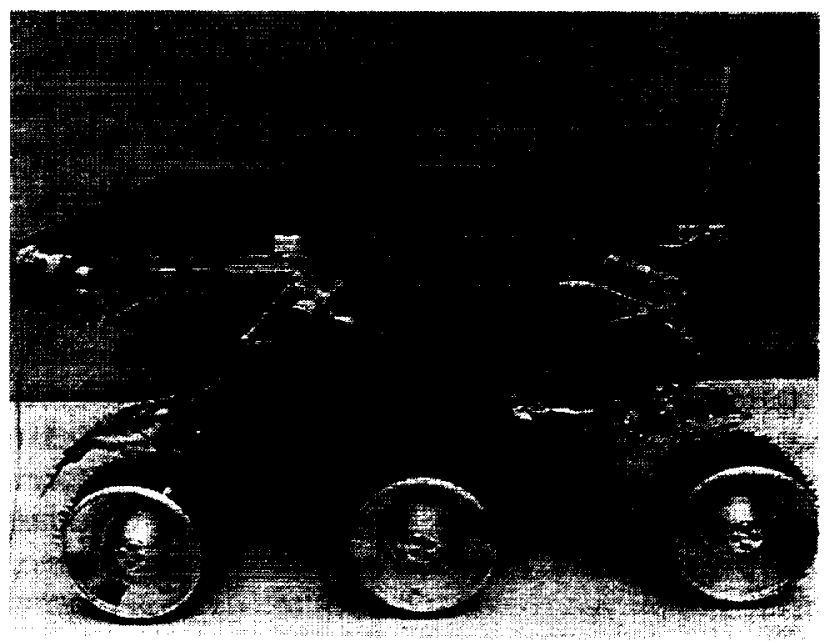

Microrover

\section{Science Payload Characteristics}

\begin{tabular}{|lll|}
\hline INSTRUMMNT & MASS (kg) & POWER (w) \\
\hline $\begin{array}{l}\text { Atmospheric Structure } \\
\text { Instrument/ Meteo rology } \\
\text { Experiment (ASI/MET) }\end{array}$ & 2.41 & 4.2 (landed) \\
\hline $\begin{array}{l}\text { Imager for Mars Pathfinder } \\
\text { (IMP) }\end{array}$ & 6.22 & 5.7 \\
\hline $\begin{array}{l}\text { Alpha-Proton X-Ray } \\
\text { Spectrometer (APXS) }\end{array}$ & .56 & 0.4 (data mode) \\
\hline
\end{tabular}



Public reporting burden for this collection of information is estimated to average 1 hour per response, including the time for reviewing instructions, searching existing data sources, gathering and maintaining the date needed, and completing and reviewing the collection of information. Send comments regarding this burden estimate or any other aspect of this collection of information, including suggestions for reducing this burden, to Washington Headquarters Services, Directorate for Information Operations and Reports. 1215 Jefferson

Davis Highway, Suite 1204, Antington, VA 22202-4302, and to the Office of Menagement and Budget, Paperwork Reduction Project (0704-0188), Washington, DC 20503.

\begin{tabular}{|l|c|c|}
\hline 1. AGENCY USE ONLY (Leave blank) & $\begin{array}{c}\text { 2. REPOAT DATE } \\
\text { November } 1996\end{array}$ & $\begin{array}{c}\text { 3. REPORT TYPE AND DATES COVERED } \\
\text { Technical Memorandum }\end{array}$
\end{tabular}

4. TITLE AND SUBTITLE

5. FUNDING NUMBERS

Wheel Abrasion Experiment Metals Selection for Mars Pathfinder Mission

6. AUTHOR(S)

Aloysius F. Hepp, Navid S. Fatemi, David M. Wilt, Dale C. Ferguson, Richard W. Hoffman, Maria M. Hill, and Alain E. Kaloyeros

\section{PERFORMING ORGANIZATION NAME(S) AND ADDRESS(ES)}

8. PERFORMING ORGANIZATION REPORT NUMBER

National Aeronautics and Space Administration

Lewis Research Center

Cleveland, Ohio 44135-3191

E-10565

9. SPONSORINGMONITORING AGENCY NAME(S) AND ADDRESS(ES)

10. SPONSORINGMONTORING AGENCY REPORT NUMBER

National Aeronautics and Space Administration

Washington, DC 20546-0001

NASA TM-107378

\section{SUPPLEMENTARY NOTES}

Prepared for the 1996 Fall Meeting sponsored by the Materials Research Society, Boston, Massachusetts, December 2-6, 1996. Aloysius F. Hepp, David M. Wilt, and Dale C. Ferguson, NASA Lewis Research Center; Navid S. Fatemi and Richard W. Hoffman, Essential Research, Inc., 2460 Fairmount Blvd., Cleveland, Ohio 44106; Maria M. Hill, Kent State University, School of Technology, Kent, Ohio 44242 (work funded by NASA Cooperative Agreement NCC3-318); Alain E. Kaloyeros, State University of New York at Albany, Department of Physics, 1400 Washington Avenue, Albany, New York 12222 (work funded by NASA Cooperative Agreement NCC3-284). Responsible person, Aloysius F. Hepp, organization code 5410, (216) 433-3835.

12a. DISTRIBUTIONAVAILABILITY STATEMENT

12b. DISTRIBUTION CODE

Unclassified - Unlimited

Subject Categories 18 and 91

This publication is available from the NASA Center for AeroSpace Information, (301) 621-0390.

13. ABSTRACT (Maximum 200 words)

A series of metals was examined for suitability for the Wheel Abrasion Experiment, one of ten microrover experiments of the Mars Pathfinder Mission. The seven candidate metals were: $\mathrm{Ag}, \mathrm{Al}, \mathrm{Au}, \mathrm{Cu}, \mathrm{Ni}, \mathrm{Pt}$, and W. Thin films of candidate metals from 0.1 to 1.0 micrometer thick were deposited on black anodized aluminum coupons by e-beam and resistive evaporation and chemical vapor deposition. Optical, corrosion, abrasion, and adhesion criteria were used to select $\mathrm{Al}, \mathrm{Ni}$, and Pt. A description is given of the deposition and testing of thin films, followed by a presentation of experimental data and a brief discussion of follow-on testing and flight qualification.

14. SUBJECT TERMS

Mars surface; Thin films; Platinum; Nickel; Aluminum; Roving vehicles; Abrasion; Mars landing

17. SECURITY CLASSIFICATION OF REPORT Unclassified
18. SECURITY CLASSIFICATION OF THIS PAGE Unclassified
15. NUMBER OF PAGES 10

16. PRICE CODE

$\mathrm{A} 02$

19. SECUAITY CLASSIFICATION
OF ABSTRACT
Unclassified
Unclassified 